\title{
Bilateral tubular minimally invasive approach for decompression, reduction and fixation in lumbosacral lythic spondylolisthesis
}

\author{
Giuseppe M.V. Barbagallo, M.D., Francesco Certo, M.D., Giovanni Sciacca, M.D., \\ and Vincenzo Albanese, M.D.
}

Neurosurgery Department, Policlinico “G. Rodolico” University Hospital, Catania, Italy

\begin{abstract}
This video demonstrates the minimally invasive surgical technique used in a 56-year-old woman suffering from L-5 spondylolysis and grade 2 L5-S1 spondylolisthesis. The first author used expandable tubular retractors bilaterally to perform neural decompression, mini-open TLIF, spondylolysthesis reduction and L5-S1 pedicle screw fixation. L-5 cement augmentation was performed through cannulated and fenestrated screws to enhance resistance to screw pull-out secondary to reduction maneuvers.

Sequential surgical steps related to microsurgery, spondylolysthesis reduction and instrumentation are shown and commented.

We submit that in cases of lythic spondylolisthesis a bilateral traversing and exiting nerve roots decompression is a safer option prior to performing the deformity reduction and fixation; the proposed minimally invasive technique may help in reducing surgical morbidity and improving postoperative recovery.

The video can be found here: http://youtu.be/G4Qdg-A-Y3M.

(http://thejns.org/doi/abs/10.3171/2013.V2.FOCUS13196)
\end{abstract}

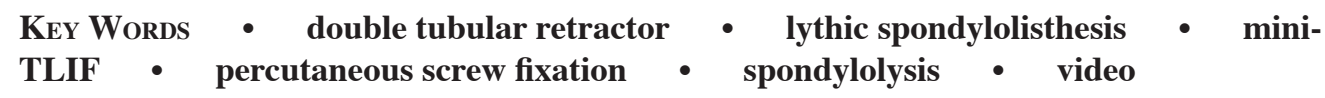

Manuscript submitted April 29, 2013

Accepted May 30, 2013.

Please include this information when citing this paper: DOI: 10.3171/2013.V2.FOCUS13196.

Address correspondence to: Giuseppe M.V. Barbagallo, M.D., Viale XX Settembre 45, 95129 Catania, Italy. email: giuseppebarbagal@hotmail.com. 